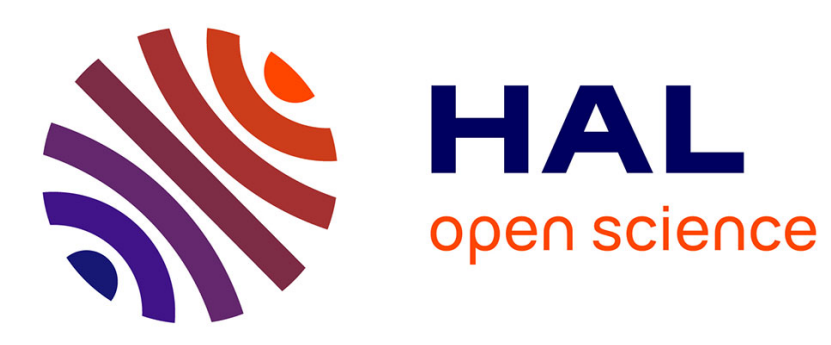

\title{
Accelerated Prompt Gamma estimation for clinical Proton Therapy simulations
}

\author{
B. Huisman, Jean Michel Létang, E. Testa, D. Sarrut
}

\section{To cite this version:}

B. Huisman, Jean Michel Létang, E. Testa, D. Sarrut. Accelerated Prompt Gamma estimation for clinical Proton Therapy simulations. International Conference on Translational Research in RadioOncology | Physics for Health in Europe (ICTR-PHE 2016), Feb 2016, Genève, Switzerland. . hal01276369

\section{HAL Id: hal-01276369 \\ https://hal.science/hal-01276369}

Submitted on 14 Feb 2017

HAL is a multi-disciplinary open access archive for the deposit and dissemination of scientific research documents, whether they are published or not. The documents may come from teaching and research institutions in France or abroad, or from public or private research centers.
L'archive ouverte pluridisciplinaire HAL, est destinée au dépôt et à la diffusion de documents scientifiques de niveau recherche, publiés ou non, émanant des établissements d'enseignement et de recherche français ou étrangers, des laboratoires publics ou privés. 


\section{Accelerated Prompt Gamma estimation for clinical Proton Therapy simulations}

2 IPNL, Université de Lyon; CNRS/IN2P3 UMR5822; Université Lyon 1 Lyon, France

brent.huisman@creatis.insa-lyon.fr

\section{PuRPose}

There is interest in the particle therapy community to use prompt gammas (PG), a natural byproduct of particle treatment, for range verification and eventually dose control (Knopf et al. 2015). However, PG production is a rare process and therefore estimating PGs exiting a patient during a proton treatment plan executed by a Monte Carlo simulation (MC) converges slowly.

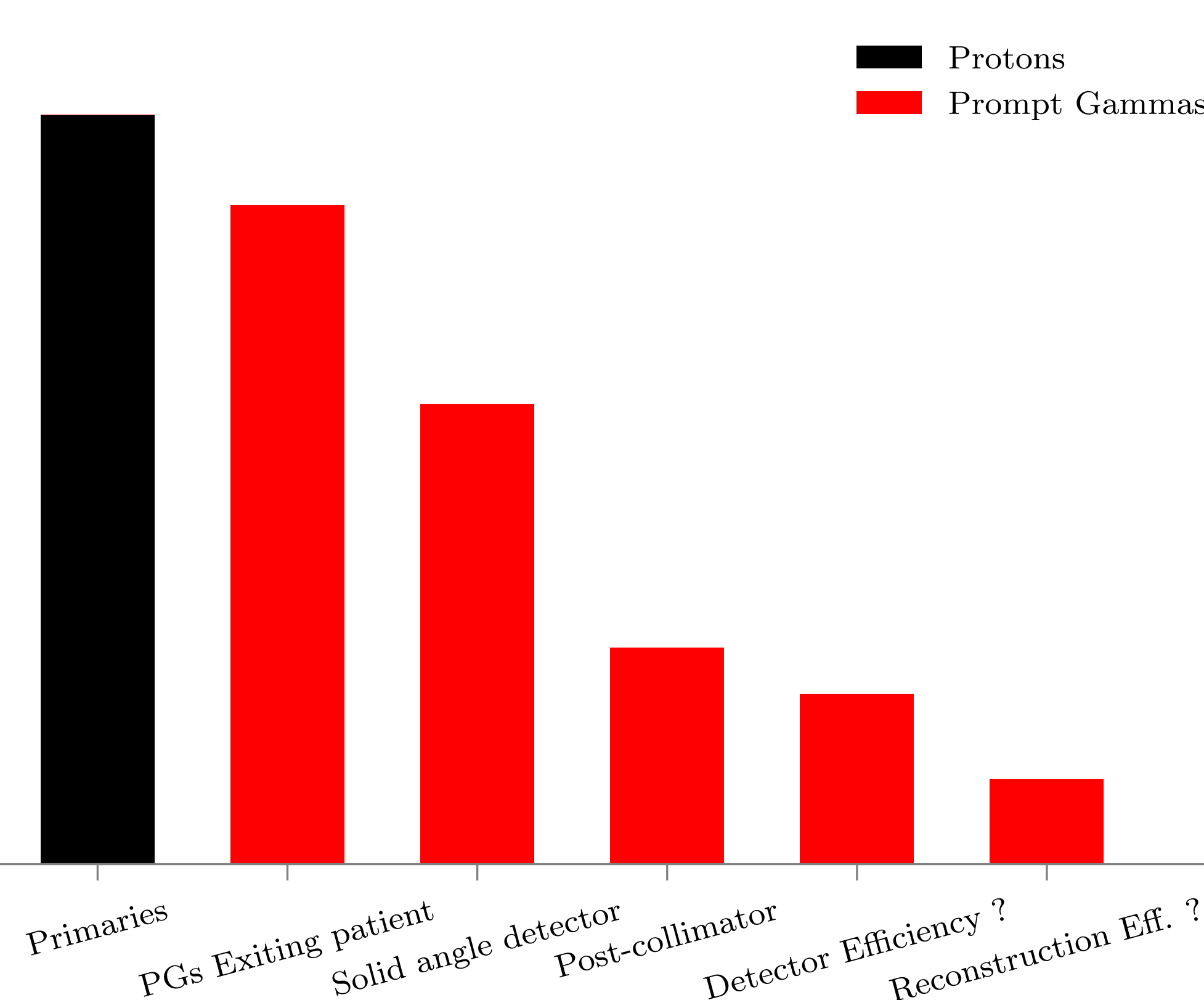

We present a generic PG yield estimator, drop-in usable with any geometry and beam configuration. We show a gain of three orders of magnitude compared to analog MC. We analyze the depth profile and the PG energy spectrum of a simple phantom and a clinical head and neck CT image.

\section{CONCEPT}

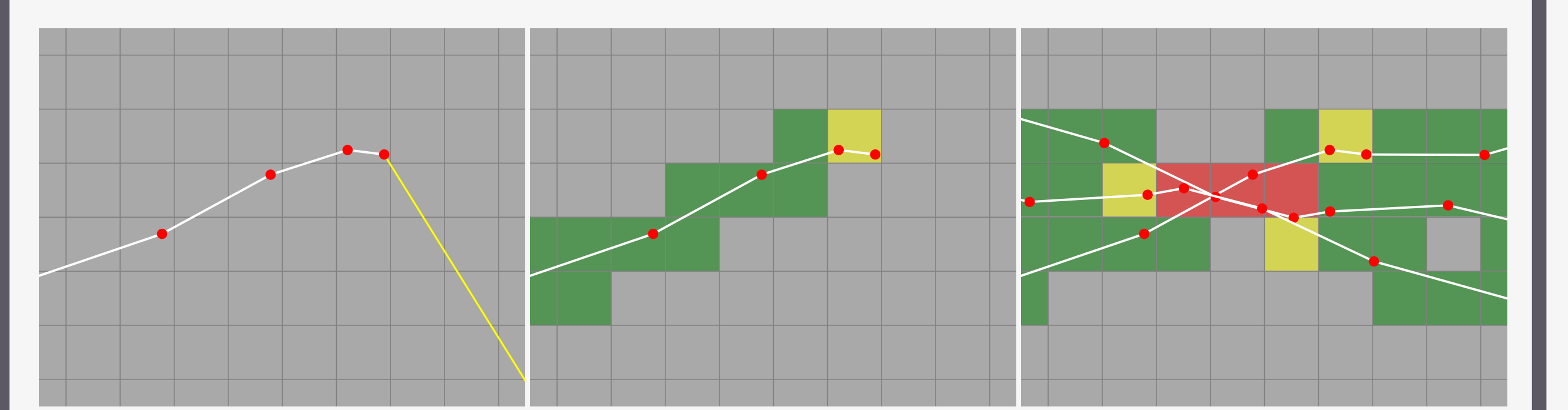

\section{Regular Monte Carlo tracking}

A regular MC simulation propagates particles throughout geometry. The propagation is broken up into steps, at which point the engine compiles a list of all possible futures, weights them, and using a random number selects the actual future. 2. At each step: Prompt Gamma production probability

Parallel to executing this conventional tracking, we may request and store the PG production probabilities. At each step, as function of $\mathrm{PG}$ energy, a production probability spectrum is stored at the current voxel.

3. Limited MC to touch all relevant voxels

By propagating a number of primary protons in this way, we obtain probabilities in all the voxels that a beam may touch. We need a minimum number of primaries, since we can only request PG probabilities in the voxels the primary passes through. However, we require fewer primary propagations with respect to a fully analog MC.

\section{ACKNOWLEDGMENTS}

This work was partly supported by Labex PRIMES ANR-11-LABX-0063, t-Gate ANR-14-CE23-0008, France Hadron ANR-11-INBS-0007 and LYric INCa-DGOS-4664.

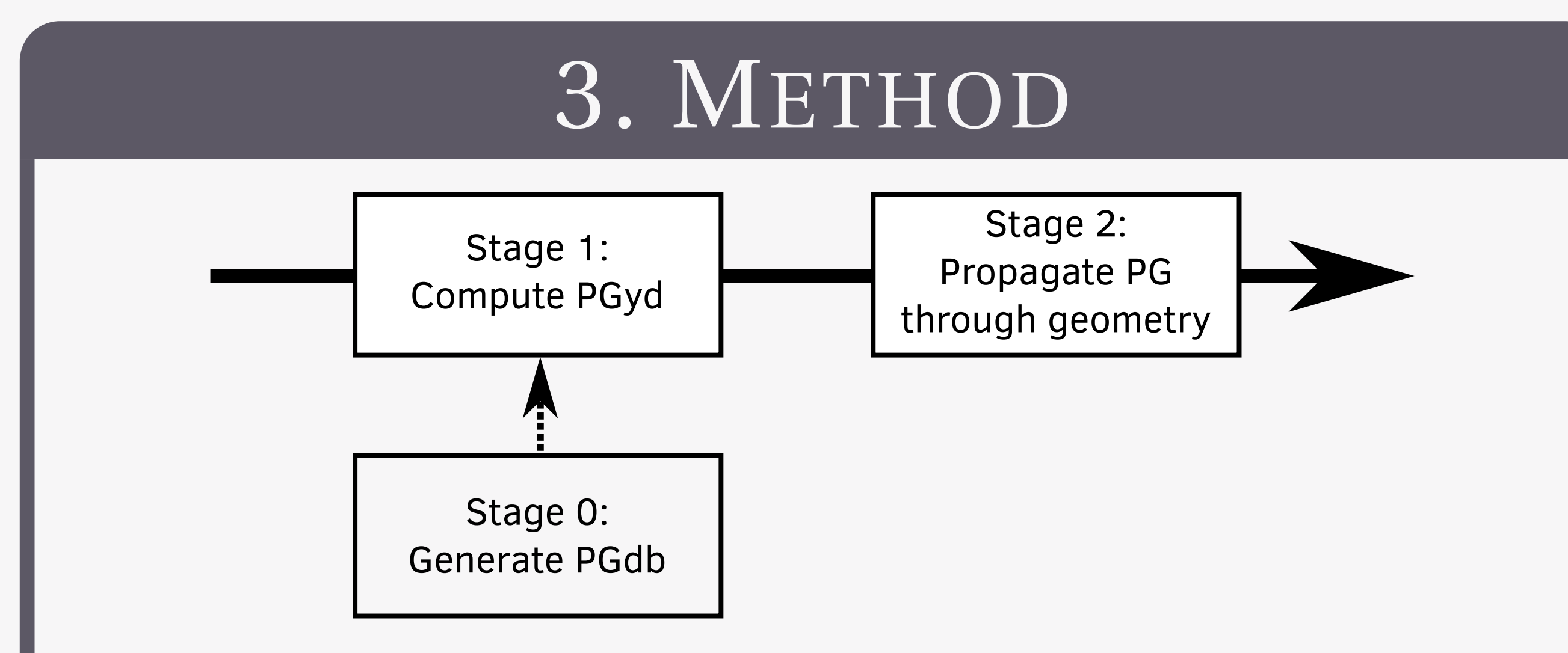

A voxelized Prompt-Gamma Track Length Estimator (Kanawati et al. 2015) simulation is broken up into two stages. A PGdb (Stage 0) is presupposed, computed once and reused. It contains an estimate of the effective linear PG production coefficient $\Gamma_{Z}$ modulo the density $\rho_{Z}$, per element $(k)$. At the start of Stage 1, the coefficients are computed for the materials found in the phantom (eq. 1).

$$
\begin{gathered}
\Gamma_{m}(E)=\rho_{m_{v}} \sum_{k=1}^{k_{m_{v}}} \omega_{k} \frac{\Gamma_{Z_{k}}(E)}{\rho_{Z_{k}}} \\
\widehat{\boldsymbol{S}}_{i}(v)=\Gamma_{m_{v}}\left(E_{g}\right) L_{g}\left(E_{g}, v\right)
\end{gathered}
$$

Per step, per voxel $v$ in the PGyd, alongside executing the analog MC processes, we compute and add the product of the step length $L_{g}$ and $\Gamma_{m_{v}}$, with $m_{v}$ the material at voxel $v$ and $g$ the proton energy bin (eq. 2). Put into words, we compute the PG yield probability energy spectrum at every step, and add it to any pre-existing spectrum in the current voxel $v$. The PGyd computed in stage 1 is used as a PG production source in Stage 2. If the user is interested in the PG signal of $10^{11}$ protons, the PGyd can be requested to give the expected output for that number of protons. Each PG is then propagated through the geometry and into the detector with regular analog MC processes.

\section{RESUlt Simple PHANTOM}
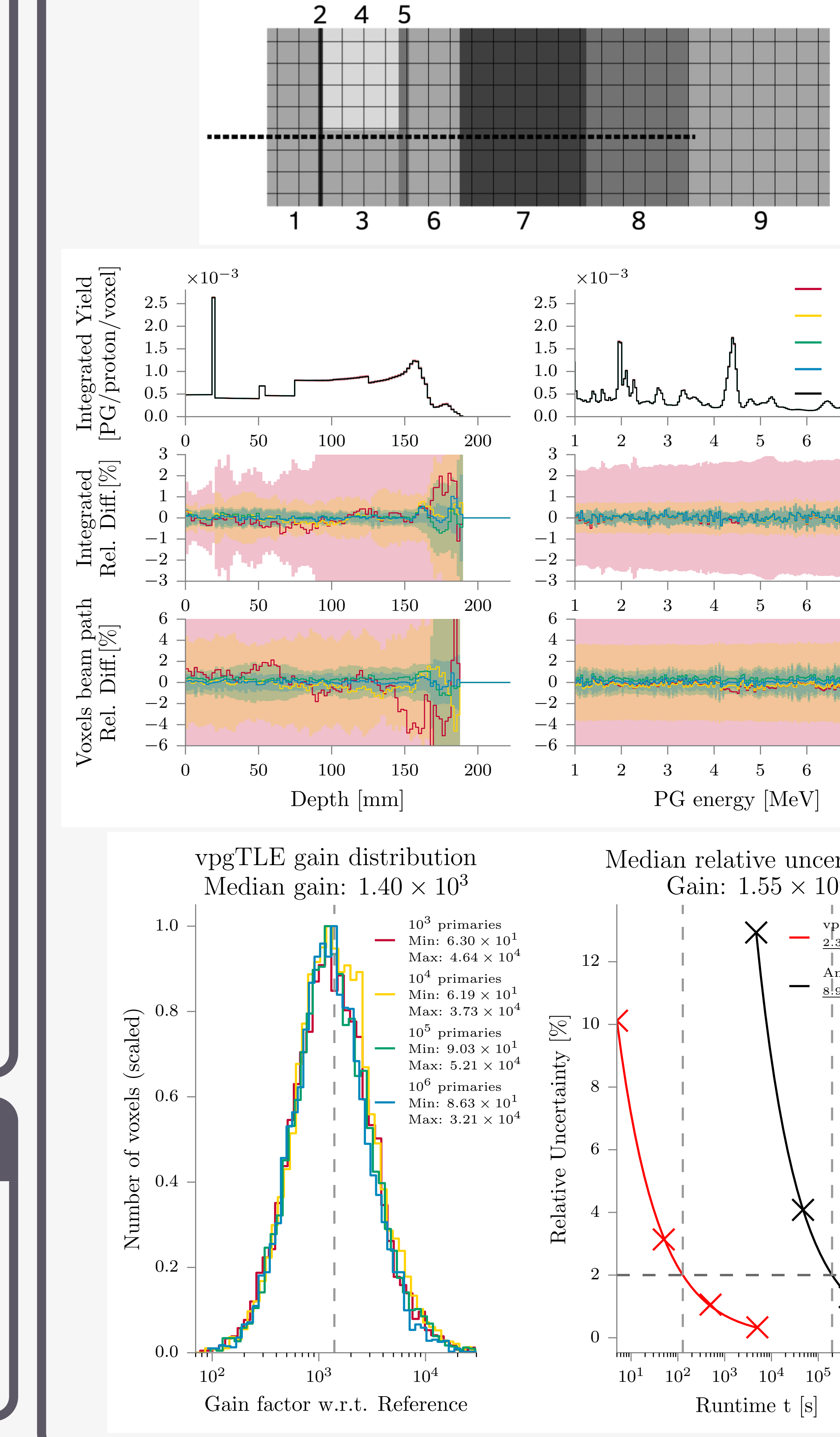

\section{RESUlt CliniCAL PHANTOM}
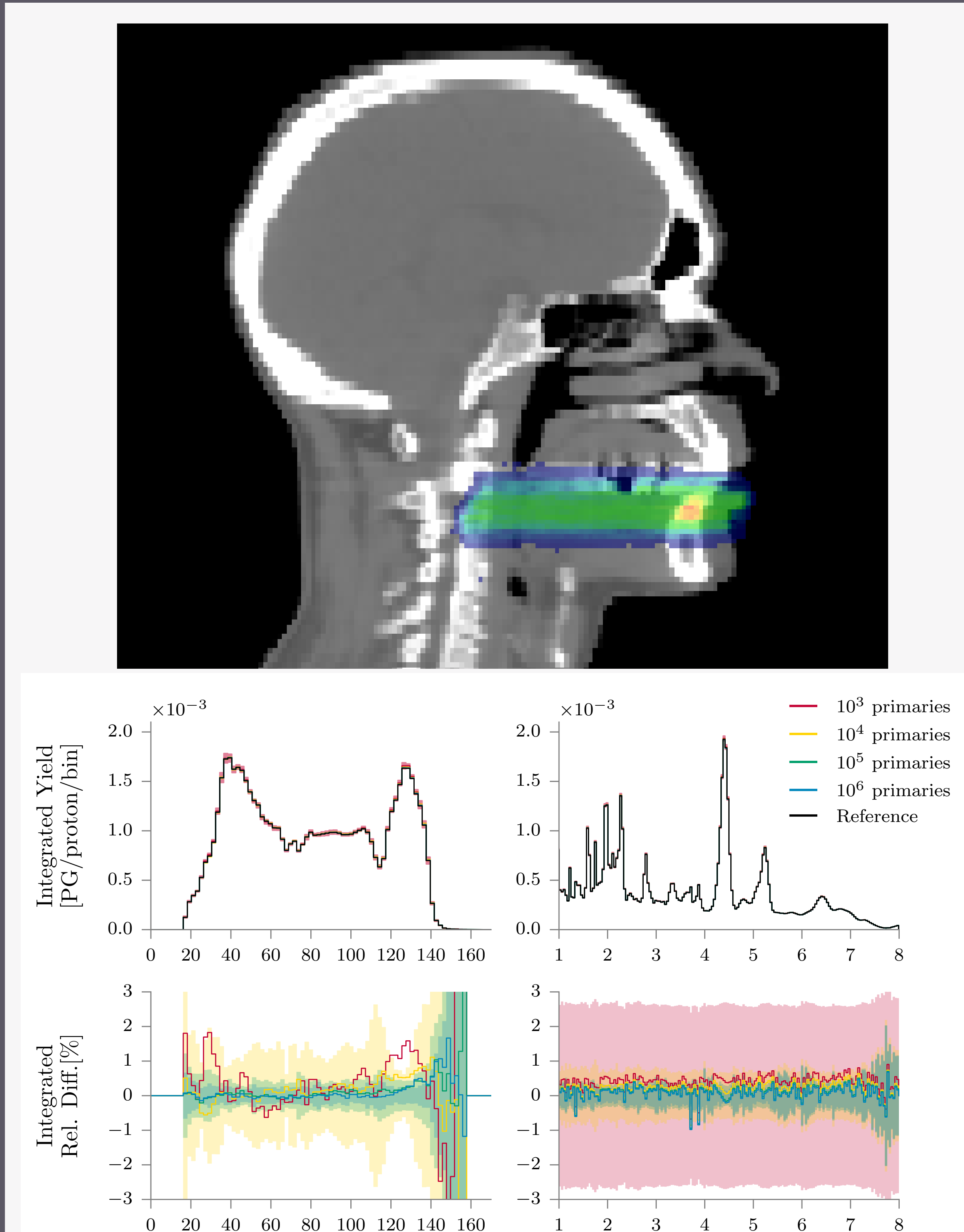

vpgTLE gain distribution

Median gain: $9.98 \times 10^{2}$
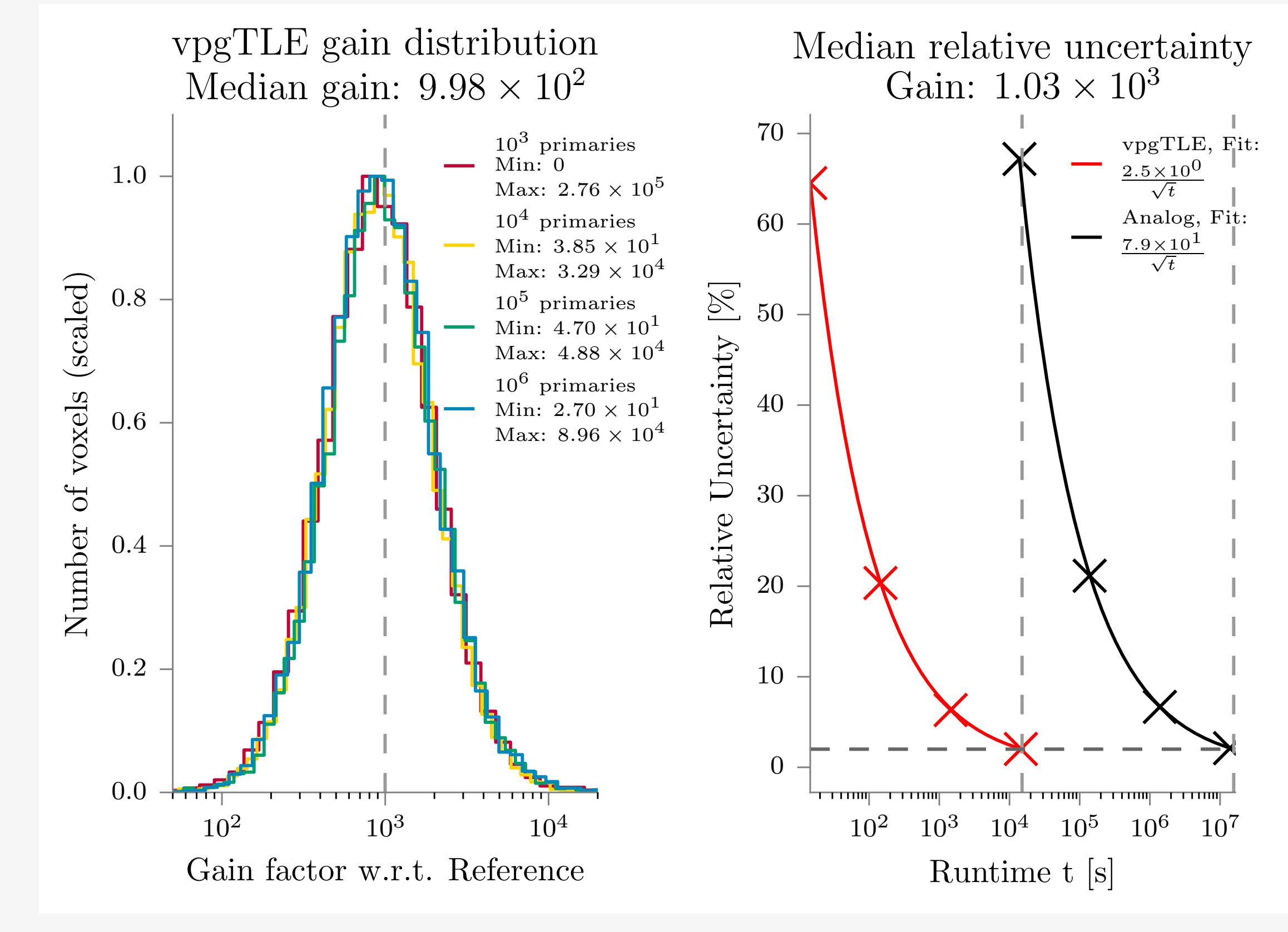

6. Conclusion

vpgTLE is a generic drop-in alternative for computing the expected PG output in voxelized geometries. The method reaches a global gain factor of $10^{3}$ for a clinical CT image and treatment plan with respect to analog MC. A median convergence of $2 \%$ for the most distal energy layer is reached in approximately four hours on a single core, with the output stabilized to within $10^{-4}$ of an analog reference simulation, when the PG yield along proton range and PG spectrum are considered. Those interested in developing and simulating PG detection devices, as well as clinicians studying complex clinical cases, may benefit from the precision and accuracy of vpgTLE simulations not offered by analytic algorithms.

The vpgTLE method is open source, fully integrated and available in the next Gate release. This study has been submitted to Physics in Medicine and Biology.

\section{REFERENCES}

Knopf et al. (2015) Phys. Med. Biol.

Kanawati et al. (2015) Phys. Med. Biol.

Sterpin et al. (2015) Phys. Med. Biol. 